\title{
Очистка от оксидов поверхности пластин полупроводника InSb для создания латеральных спиновых клапанов
}

\author{
(С) Н.А. Виглин, И.В. Грибов, В.М. Цвелиховская, Е.И. Патраков \\ Институт физики металлов им. М.Н. Михеева Уральского отделения Российской академии наук, \\ 620990 Екатеринбург, Россия \\ E-mail: viglin@imp.uran.ru
}

(Получена 14 мая 2018 г. Принята к печати 21 июля 2018 г.)

\begin{abstract}
Изучались условия создания гладкой и освобожденной от оксидов поверхности полупроводника InSb c целью создания на его основе латеральных спиновых устройств. Исследовалась скорость сухого травления ионами $\mathrm{Ar}$ поверхности слоев кристаллических граней (100) пластин полупроводника InSb, a также изменение их шероховатости в зависимости от мощности подводимой к усройствам ионного травления. Оценивалась степень окисления поверхности полупроводника, экспонированного на воздухе после ионной чистки и отжига в молекулярном водороде. На основе сравнения эффективности спиновой инжекции в устройствах, созданных с полупроводниками, подвергшимися различной обработке, сделан вывод о параметрах оптимальной подготовки поверхности пластин $\mathrm{InSb}$ для изготовления латеральных спиновых устройств.
\end{abstract}

DOI: 10.21883/FTP.2019.02.47113.8906

\section{1. Введение}

Полупроводниковая спинтроника за последние три десятилетия прошла путь от принципиальных идей спинового транзистора [1] до реализации спиновых устройств с электрическими инжекцией и детектированием поляризованных по спину электронов в полупроводниках $\mathrm{Si}$ [2], GaAs [3] и InSb [4]. Весьма важную роль в успешной инжекции спин-поляризованного тока играет качество интерфейса полупроводника и ферромагнитного металлического инжектора, которое предполагает совершенство структуры и состава этих материалов, четкую (без взаимной диффузии) и гладкую границу между ними. Между полупроводником и металлом может находиться туннельный барьер, представляющий собой тонкий слой диэлектрика, толщиной $1-2$ нм, необходимый для улучшения эффективности инжекции поляризованных электронов [5]. В качестве диэлектрика используют оксиды алюминия, кремния, магния и некоторые другие. Барьер должен быть сплошным и не содержать сквозных отверстий (pinhole). Вероятность формирования дефектов такого типа высока на неровных поверхностях, поэтому величина шероховатости поверхности не должна быть больше толщины туннельного барьера.

Для создания качественных интерфейсов обычно используется наращивание тонкого слоя полупроводника на подложку, кристаллографические параметры которой соответствуют эпитаксиальному росту монокристаллической пленки полупроводника. В качестве подложки может использоваться пластина того же полупроводника. Необходимую электронную проводимость получают путем легирования эпитаксиального слоя. Затем в условиях высокого вакуума наносят последовательно слои диэлектрика (туннельный барьер) и ферромагнитного металла. Такая схема изготовления интерфейса позволяет получать многослойные структуры с контролируемыми свойствами.
Технологии эпитаксиального роста пленок $\mathrm{Si}$ и $\mathrm{GaAs}$ хорошо разработаны, так как эти полупроводники широко используются в промышленном производстве электронных приборов, тогда как для полупроводника $\mathrm{InSb}$ методы эпитаксиального роста пленок находятся в стадии исследований [6]. Особый интерес к InSb обусловлен тем, что он обладает наименьшей шириной запрещенной зоны среди полупроводников группы $\mathrm{A}^{\mathrm{III}} \mathrm{B}^{\mathrm{V}}$ и перспективен в качестве материала для детекторов средневолнового ИК-диапазона [7]. Также этот полупроводник обладает рекордной в своей группе подвижностью электронов $\left(\mu=1.2 \cdot 10^{6} \mathrm{~cm}^{2} / \mathrm{B} \cdot\right.$ с при $\left.77 \mathrm{~K}\right)[8]$ и огромной по сравнению с другими полупроводниками длиной спиновой диффузии $\left(L_{S}=25\right.$ мкм при $\left.77 \mathrm{~K}[4]\right)$, что делает его привлекательным для использования в полупроводниковой спиновой электронике.

\section{2. Образцы и методика эксперимента}

В настоящей работе исследовались методы удаления оксидов In и $\mathrm{Sb}$ с поверхности (100) пластин $\mathrm{InSb}$ размером $10 \times 10 \times 0.4 \mathrm{MM}$, которые использовались в качестве подложек для создания латеральных спиновых клапанов со структурой „ферромагнитный ме-

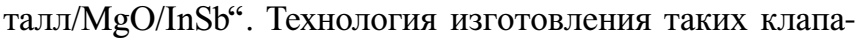
нов предполагает несколько фотолитографических операций, при которых поверхность пластины полупроводника контактирует с различными жидкими материалами и атмосферой воздуха. Изучались параметры сухого травления поверхности полупроводника ионами аргона, а также удаления поверхностных оксидов путем отжига в молекулярном водороде. Оценивалась скорость нарастания оксидной пленки в атмосфере воздуха после этих процедур. Химический состав поверхностных слоев контролировался методом рентгеновской фотоэлектронной спектроскопии (РФЭС), а шероховатость 
поверхности - методом атомно-силовой микроскопии (АСМ). Цель исследований заключалась в определении оптимальных технологий очистки поверхности (100) пластины полупроводника $\mathrm{InSb}$ от оксидной пленки без существенного ухудшения ее шероховатости.

\section{3. Экспериментальные результаты и обсуждение}

Были исследованы степень окисления пластины после стандартных процедур чистки поверхности в органических растворителях и дистиллированной воде, после удаления поверхностных оксидов бомбардировкой ионами $\mathrm{Ar}$ и экспозицией образцов на воздухе. Также изучалась степень окисления пластины InSb после отжига в атмосфере водорода и последующей выдержкой образца на воздухе. Отжиг в атомарном и молекулярном водороде используется для удаления оксидов с поверхности полупроводников. В частности, в работе [7] описан метод удаления оксидов с поверхности пластин $\mathrm{InSb}$ при низком давлении молекулярного водорода $\left(P_{\mathrm{H}_{2}}=6.5 \cdot 10^{-6}\right.$ мБар) и температуре $250^{\circ} \mathrm{C}$ в течение 0.5 ч. В описанном в этой работе методе, после отжига образцы должны оставаться в вакууме для предотвращения окисления поверхности.

На рис. 1 приведены РФЭС-спектры в области $\mathrm{Sb}(3 d)$ для образцов InSb c различной обработкой. Интенсивность линий дана в относительных единицах. Спектры смещены по вертикальной оси для удобства сопоставления. РФЭС позволяет наблюдать изменение энергии связи атомов в зависимости от их химического состояния в тонком поверхностном слое образца. Пики атомов $\mathrm{Sb}(3 d)$, образующих химическую связь с атомами кислорода, смещены в сторону бо́льших энергий связи. В приведенных на рис. 1 спектрах наблюдаются пики

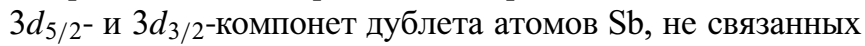
с атомами кислорода (положение максимумов - 527.5 и 536.9 эВ соответственно), а также пики поверхностных оксидов $\mathrm{Sb}$ (530.2 и 539.4 эВ). Также присутствует пик с энергией связи 530 э, соответствующий $\mathrm{O}(1 s)$ и практически совпадающий с пиком $\mathrm{Sb}\left(3 d_{5 / 2}\right)$ в оксиде. Значения энергии связи для окисленной и не окисленной $\mathrm{Sb}$ удовлетворительно совпадают с приведенными в литературе [7].

Кривая 1 иллюстрирует состояние поверхности образца после процедур очистки в органических растворителях и дистиллированной воде. Видно, что линии окисленной и не окисленной $\mathrm{Sb}$ имеют примерно одинаковую интенсивность. После сухого травления ионами $\mathrm{Ar}$ на глубину 1 нм интенсивность линий, соответствующих окисленной $\mathrm{Sb}$, уменьшилась (кривая 2).

Кривая 3 демонстрирует состояние поверхности образца после процедур очистки в органических растворителях и дистиллированной воде, отжига в атмосфере водорода при температуре $150^{\circ} \mathrm{C}$ в течение 1 ч и остывания в течение 2 ч (также в $\mathrm{H}_{2}$ ), а затем последующего экспонирования на воздухе в течение 20 мин.

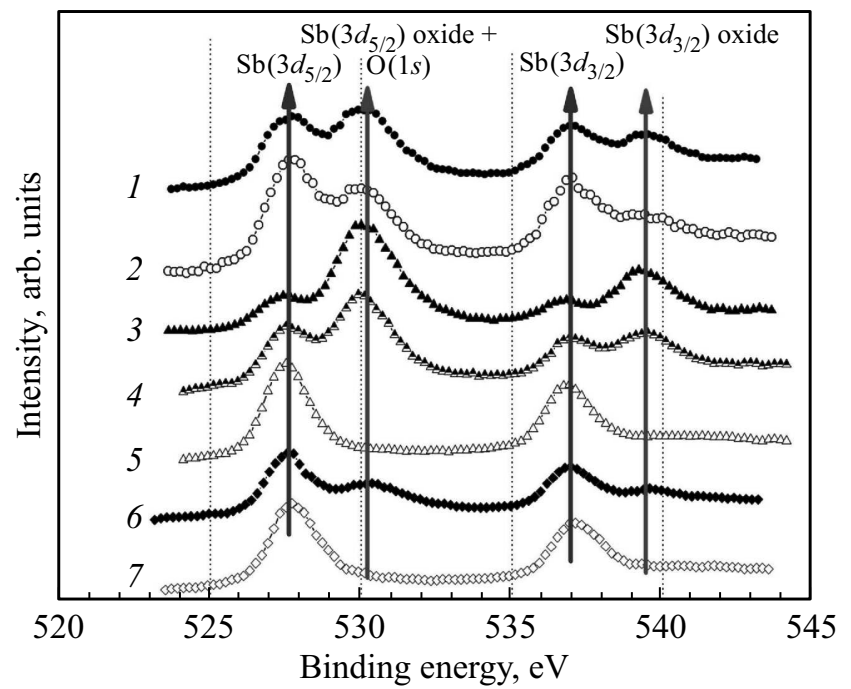

Рис. 1. РФЭС-спектры в области $\mathrm{Sb}(3 d)$ показывают прогресс удаления и появления оксида в результате различных операций: 1 - после стандартной очистки и сушки на воздухе, 2 - травление поверхности на глубину 1 нм, 3 - окисление на воздухе в течение 20 мин после отжига в молекулярном водороде, 4 - травление поверхности на глубину 1 нм, 5 - дополнительное травление поверхности на глубину 3 нм, 6 - окисление на воздухе в течение 20 мин, 7 - травление поверхности на глубину 1 нм. Во всех случаях травление производилось ионами Ar.

Видно, что интенсивность линий, соответствующих оксидам сурьмы, существенно выросла по сравнению со спектром 1. Это можно объяснить выросшей абсорбционной активностью поверхности полупроводника из-за появления в результате отжига в $\mathrm{H}_{2}$ свободных связей атомов $\mathrm{Sb}$ и In. Даже короткий контакт поверхности образца с атмосферой, содержащей кислород, приводит к более интенсивному по сравнению с первоначальным окислению поверхности.

Кривая 4 отображает состояние поверхности $\mathrm{InSb}$ после травления этого образца на глубину 1 нм ионами Ar, кривая 5 - после дополнительного травления еще на 3 нм. На кривой 4 присутствуют линии, соответствующие оксидам $\mathrm{Sb}$, тогда как на спектре 5 эти линии полностью отсутствуют.

Спектр 6 соответствует этому же образцу, экспонированному в атмосфере воздуха в течение 20 мин. Видно, что поверхность окислилась, причем степень окисления существенно меньше, чем на спектре 3 (20 мин на воздухе после отжига в водороде), даже после естественного окисления (спектр 1). Спектр 7 - травление на глубину 1 нм вновь освобождает поверхность от оксидов.

На рис. 2 представлена скорость травления плоскости (100) пластины полупроводника InSb в зависимости от мощности, подводимой к устройству ионного травления. Приведены усредненные данные, полученные при исследовании двенадцати образцов (по три образца на каждую точку). На поверхность пластины наносилась защитная полоска нитролака, производилось 


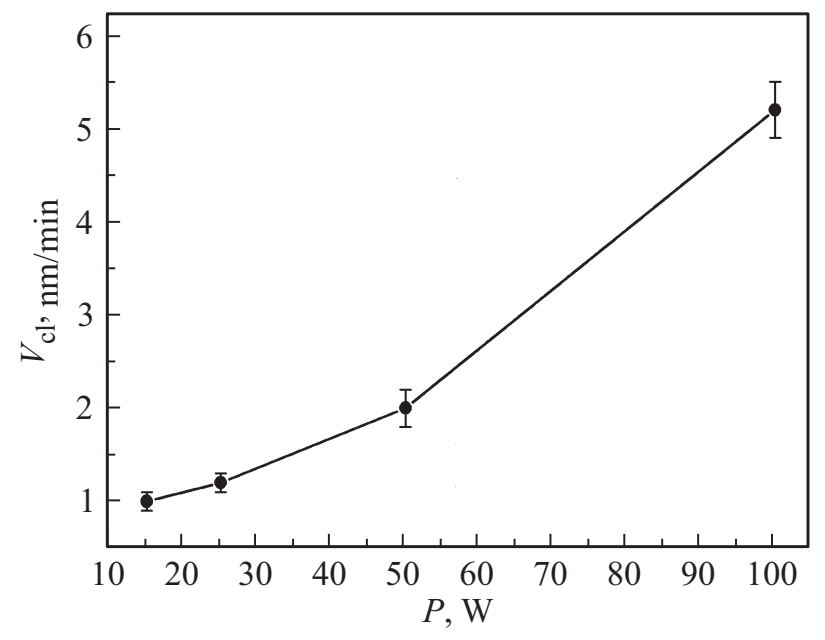

Рис. 2. Зависимость скорости травления $V_{\text {cl }}$ от мощности $P$, подводимой к устройству ионного травления. Давление аргона $10^{-2}$ мБар.

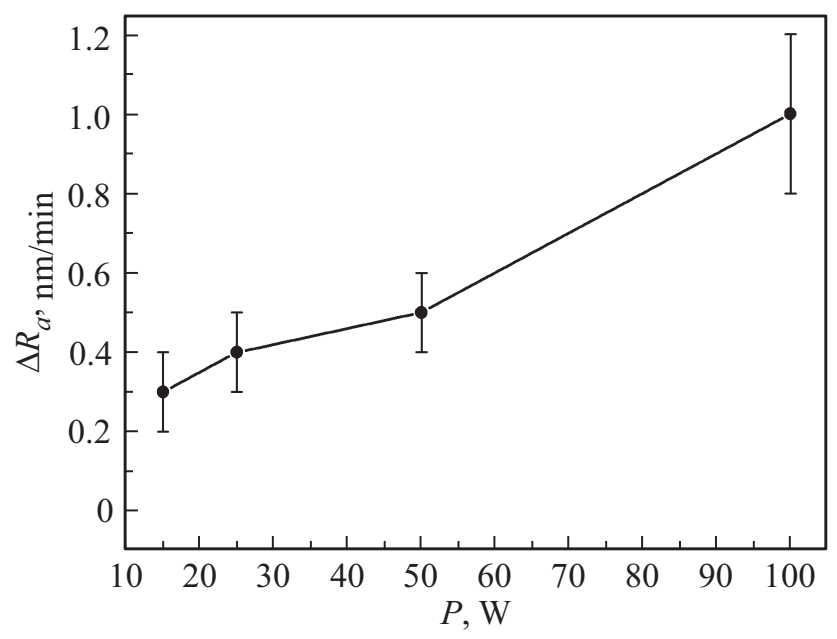

Рис. 3. Скорость увеличения шероховатости $\Delta R_{a}$ в зависимости от мощности $P$, подводимой к устройству ионного травления. Давление аргона $10^{-2}$ мБар.

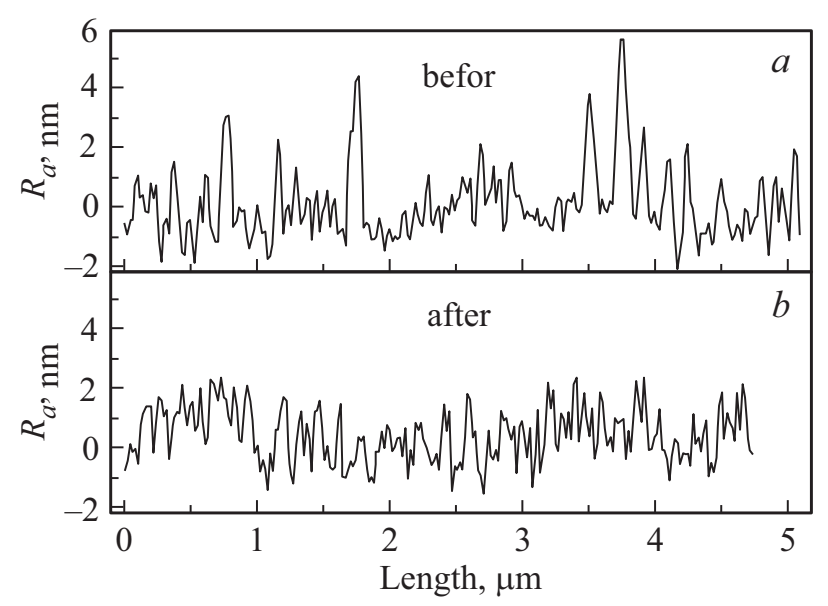

Рис. 4. Профиль шероховатости поверхности (100) пластины $\mathrm{InSb}$, полученный на $\mathrm{ACM}$ для одного и того же участка: $a$ - до травления, $b-$ после травления в течение 5 мин ионами $\mathrm{Ar}$ при $P=25 \mathrm{~B}$.

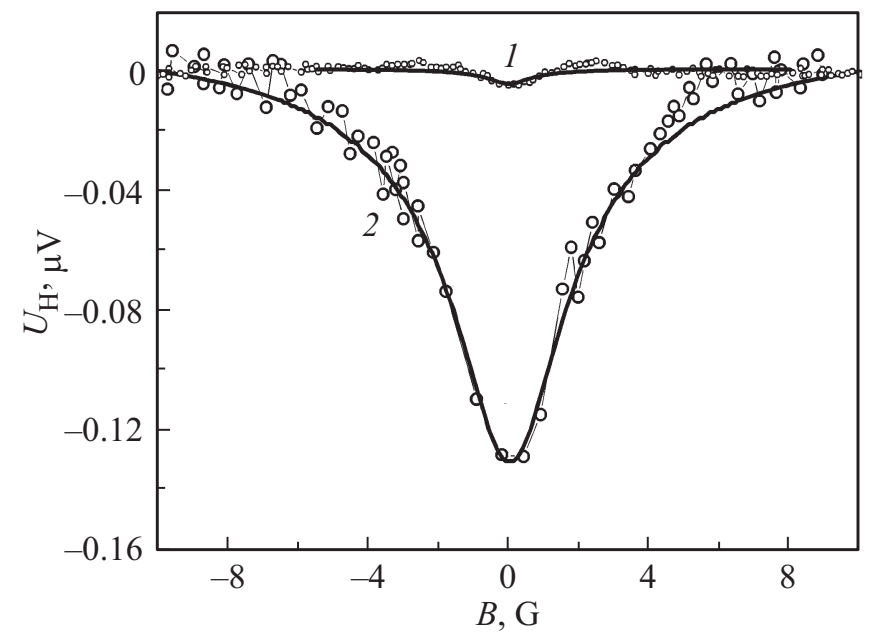

Рис. 5. Напряжение $U_{\mathrm{H}}$, создаваемое поляризованными по спину электронами в InSb при эффекте Ханле в латеральных спиновых устройствах. Ток инжектора 15 мкА. 1 - при изготовлении устройства поверхность InSb очищалась ионами $\mathrm{Ar}$ в течение 3 мин при мощности $100 \mathrm{~B}$, 2 - при изготовлении устройства очистка поверхности InSb ионами $\mathrm{Ar}$ в течение 1.5 мин при мощности 25 Вт. Кружки - экспериментально измеренное напряжение, сплошные кривые - теоретический расчет с помощью формул, приведенных в работе [4].

ионное травление, после чего защитная полоска смывалась. В районе возникшей „ступеньки“ с помощью АСМ проводились измерения глубины травления, также оценивалась шероховатость поверхности. Данные по скорости изменения шероховатости $\Delta R_{a}$ показаны на рис. 3. При мощности, подводимой к устройству ионного травления $\sim 15-25$ Вт, скорость увеличения шероховатости поверхности составляет $0.3-0.4 \mathrm{Hм} / \mathrm{Mин,} \mathrm{также}$ при этом происходит некоторое нивелирование максимальных отклонений профиля шероховатости (рис. 4).

Задачей исследований была подготовка поверхности полупроводника $\mathrm{InSb}$ для изготовления латерального спинового устройства. Это устройство представляло собой несколько узких (шириной около 4 мкм) металлических ферромагнитных контактов (из $\mathrm{Fe}$ или $\mathrm{CoFe}$ ), расположенных на (100) поверхности пластины InSb параллельно друг другу с шагом $\sim 10$ мкм. Контакты изготавливались магнетронным распылением и формировались фотолитографическими методами. Между полупроводником и металлическими контактами располагался туннельный барьер из $\mathrm{MgO}$ толщиной $1.8-2$ нм, который наносился магнетронным распылением на очищенную от оксидов поверхность InSb. C помощью такого латерального спинового устройства можно исследовать процессы инжекции и транспорта спин-поляризованных электронов в немагнитных полупроводниках. В частности, можно оценить величину спиновой поляризации электронов, создаваемой в полупроводнике инжекцией спин-поляризованного тока из ферромагнитного металлического контакта-инжектора. Спиновая поляризации электронов в полупроводнике вызывает отклонение 
от равновесного значения контрактной разности потенциалов между полупроводником и ферромагнитным контактом-детектором. Детектор чувствителен к взаимному направлению намагниченности самого детектора и эффективной намагниченности электронного газа в полупроводнике. При измерении напряжений, вызванных спин-поляризованными электронами, обычно переключают направление эффективной намагниченности электронов относительно направления намагниченности детектора. Сделать это можно, например, с помощью магнитного поля, прикладываемого поперечно направлению намагниченности электронного газа (эффект Ханле). Методика измерения напряжения эффекта Ханле описана в работах $[4,9]$. На рис. 5 приведены результаты измерений напряжения эффекта Ханле, создаваемого поляризованными электронами на детекторе в этом устройстве, когда $\mathrm{MgO}$ напылялся на поверхность полупроводника с высокой и низкой шероховатостью, созданной в результате очистки поверхности ионами $\mathrm{Ar}$ за 3 мин при мощности 100 Вт и 1.5 мин при 25 Вт соответственно. Шероховатость поверхности перед травлением ионами $\mathrm{Ar}$ составляла 0.7-1 нм. Видно, что эффективность спиновой инжекции, которая пропорциональна напряжению $U_{\mathrm{H}}$, существенно выше в устройстве с гладкой поверхностью полупроводника.

\section{4. Заключение}

Таким образом, для удаления оксидов с плоскости (100) пластины InSb, подвергавшейся естественному окислению на воздухе, необходимо травление ионами $\mathrm{Ar}$ на глубину 1.5-2 нм. Для пластин, окисленных в воздухе после отжига в молекулярном водороде, требуется травление на глубину 4 нм. Ухудшение шероховатости поверхности пластин при травлении пропорционально мощности, подводимой к устройству ионного травления. При травлении на глубину до 4 нм целесообразно ограничить мощность источника ионного травления до $15-25 \mathrm{BТ}$.

Работа выполнена в рамках государственного задания ФАНО России (тема „Спин“, № АААА-А18118020290104-2) при поддержке Министерства образования и науки РФ (грант 14.Z50.31.0025) и РФФИ (проект № 16-02-00044).

\section{Список литературы}

[1] S. Datta, B. Das. Appl. Phys. Lett., 56, 665 (1990).

[2] O.M.J. van't Erve, A.L. Friedman, E. Cobas, C.H. Li, J.T. Robinson, B.T. Jonker. Nature Nanotechnol., 7, 737 (2012).

[3] X. Lou, C. Adelmann, S.A. Crooker, E.S. Garlid, J. Zhang, S.M. Reddy, S.D. Flexner, C.J. Palmstrøm, P.A. Crowell. Nature Phys., 3, 197 (2007).

[4] N.A. Viglin, V.V. Ustinov, S.O. Demokritov, A.O. Shorikov, N.G. Bebenin, V.M. Tsvelikhovskaya, T.N. Pavlov, E.I. Patrakov. Phys. Rev. B, 96, 235303 (2017).
[5] G. Schmidt, D. Ferrand, L.W. Molenkamp, A.T. Filip, B.J. van Wees. Phys. Rev. B, 62, R4790(R) (2000).

[6] А.Е. Мирофянченко, Е.Д. Коротаев, Н.И. Яковлева. Прикл. физика, 3, 55 (2014).

[7] R. Tessler, C. Saguy, O. Klin, S. Greenberg, E. Weiss, R. Akhvlediani, R. Edrei, A. Hoffman. Appl. Phys. Lett., 88, 031918 (2006).

[8] А.Я. Нашельский. Технология спещматериалов электронной техники (М., Металлургия, 1993).

[9] N.A. Viglin, V.V. Ustinov, V.M. Tsvelikhovskaya, T.N. Pavlov. JETP Lett., 101, 113 (2015).

Редактор А.Н. Смирнов

\section{Creating oxide-free InSb surface for producing lateral spin valves}

\section{N.A. Viglin, I.V. Gribov, V.M. Tsvelikhvskaya, E.I. Patrakov}

Miheev Institute of Metal Physics, Ural Branch of Russian Academy of Sciences, 620990 Ekaterinburg, Russia

Abstract Methods how to produce smooth and oxides-free InSb surface suitalbe for creating lateral spintronics devices were studied. The dry etching of (100) plane face with Ar ions was used. The rate etch and the surface roughness were found as a function of the power used in the ion-etch apparatus. Oxidation level of the surface after ion-beam cleaning, air exposure and heating in $\mathrm{H}_{2}$ atmosphere was determined. The lateral devices on $\mathrm{InSb}$ surface after different treating were created and the optimal parameters of the process of preparation of InSb surface are found by comparing the spin-injection of the devices. 